\title{
Is creative work sustainable? Understanding identity, motivation and worth
}

\begin{abstract}
The purpose of this article is to explore the 'value' of creative workers work from their perspective. The work of this group is often ephemeral and intangible, contributes to the development of society, and is often very poorly remunerated. Qualitative responses from a large survey of creative workers work experience and attitudes have provided the material analysed for this paper. The data was analysed using a naturalistic coding process leading to the emergence of themes describing the data. Five 'elements of worth' emerged which included identity representation, motivation, catalysts of creativity, interactions with society and recognition. Knowing how creative workers experience these five elements, provides educators and local/national policy makers data on which to base their pedagogical and financial judgements. To date there has been no other study that examines how creative workers perceive the value of their work and how that notion of value is derived from their lived experience.
\end{abstract}

\section{Keywords}

Creative workers, identity, motivation.

\section{Introduction}

Creative workers have often been neglected in research on work and life goals simply because of the difficulty of describing what they do, how they contribute to society and culture, the breadth of their work, their financial contribution to the economy, and their critical role for cultural heritage and sustainability (Petocz et al., 2014). Inside this nebulous area, creative workers identify strongly with their art forms, but this personal identity can shift in response to social situation or with the (multiple) values associated with their work. Creative work is considered an intangible asset as part of the United Nations' fourth pillar of sustainability and contributes to cultural heritage and cultural sustainability (Duxbury et al., 2012). Understanding the context and goals of creative workers provides us with a means of understanding this intangible asset from the perspective of those involved in its promulgation (Reid et al., 2011), and therefore, how it may be possible to align higher education in the creative arts to the exigencies of creative work.

Reid, A., Bennett, D., \& Petocz, P. (In press). Creative workers' perceptions of worth: Understanding identity and motivation in a complex workforce. Australian Journal of Career Development. Accepted December 2015. 
This paper reports findings from research on the characteristics and economic circumstances of creative workers in Perth, Australia. One of the research priorities was to analyze creative workers' perceptions of the value of their work and the part that it plays in the ecology of cultural sustainability. Such an exploration enables us to see the societal scope of this work. Statistics show that cultural and creative activity contributed \$86 billion to Australia's GDP in 2008-09 (Australian Bureau of Statistics, 2014) and $85 \%$ of Australians believe the arts make for a richer and more meaningful life (Australia Council, 2014). Yet many creative workers have a perception that the community has little appreciation of their work. We identify five emergent elements that describe the ways in which creative workers perceive the worth of their creative contributions: identity representation; motivation; creative catalyst; interaction with society; and recognition. We argue that understanding these elements can help educators, policy makers and funding bodies better appreciate the complexities of this diverse workforce.

Creative workers contribute through their largely intangible work to the cultural identity and economic health of contemporary society. These artists play an important societal role as their work reflects contemporary cultural style, makes homage to past practices, and pushes forward into new and innovative practice. In some instances their work is recorded or published and remembered formally, but in many more it is of the moment. The majority of creative workers are in roles that are missed by statistical workforce surveys such as national census collections, which focus on people employed in large-scale organizations such as orchestras, art galleries and film studios. Extant survey and census-based research tends to emphasize workers' 'main occupation' and understates or overlooks other aspects of the portfolio of work that is commonplace within the creative industries (Bennett and Bridgstock, 2014). As a result, the artist population is likely to be underestimated by more than 50 per cent (Throsby, 2008). Over-emphasis on established or company-based creative workers results in skewed assessments of creative work. For example, drawing on census-based research findings Cunningham (2011, p. 4) asserts that "creative workers have incomes above national averages, in some cases, considerably above - except for music and performing arts, which typically aggregate below national averages." However, very few of the creative workers in our more-nuanced study reported excellent incomes; rather, they fell into the second bracket with incomes "below national averages". In reality, creative workers Reid, A., Bennett, D., \& Petocz, P. (In press). Creative workers' perceptions of worth: Understanding identity and motivation in a complex workforce. Australian Journal of Career Development. Accepted December 2015. 
have a rather more intimate and individual approach to the work that they do. This often has an unfortunate effect on their personal economy as it is may be hard for them to attract remuneration for their creative work at a scale that would see them fully employed in their specific field of creative endeavour.

Despite this apparent lack of financial reward, creative workers remain passionately involved in their work, seeking and inventing opportunities to contribute to society. Taylor and Littleton (2012, p. 135) suggest that this contribution is "associated with freedom, difference or specialness, and with work that is personal." This characterization of the creative worker is a long-held social trope, exemplified by the bohemian artist starving in a garret (Parry, 1933; Nicholson, 2003; Eikhof and Haunschild, 2006). There is something noble about personal sacrifice for an art form. However, in a contemporary world that relies on swift knowledge acquisition and transfer, the independence of such an artist is no longer viable. To this end, Taylor and Littleton (2012, p. 138) surmise that 'doing your 'own' work remains an ideal but one that is recognized to be dependent on others", yet this dependence appears to be financial rather than artistic: "the specialness and freedom of being creative are associated ... with a rejection of constraints attributed to other contemporary careers."

A common term describing such complex working arrangements is 'portfolio career', referring to a collection of multiple, concurrent jobs. In an ideal scenario, such a portfolio is pro-actively assembled to suit individual needs (Handy, 1989). At the extreme, portfolio careers typical of the creative industries are those described as 'protean', after the mythological Greek sea-god Proteus who would use his knowledge of the future to change form and avoid danger. Hall (1976) first coined the term to describe careers driven by an individual's core values and subjective indicators of success. For creative workers, however, the avoidance of danger is often a reactive manoeuvre to remain employable and attractive to the market.

In this paper, we explore these concerns and questions from the perspective of creative workers who live under these constraints. Their stories show that selfidentification as a creative worker is both personally and socially constructed, and that identity shifts according to opportunity. Characteristically, these creative workers demonstrate a drive and passion that may be likened to the most brilliant commercial entrepreneurs, but generally without the associated financial reward.

Reid, A., Bennett, D., \& Petocz, P. (In press). Creative workers' perceptions of worth: Understanding identity and motivation in a complex workforce. Australian Journal of Career Development. Accepted December 2015. 


\section{Theoretical Framework and Approach}

Our previous research (Bennett, Reid and Petocz, 2015) has suggested that the ability of artists to construct broad professional identities is directly related to perceived alignment between creative work and the self. In seeking to explore this in a creative context, our work draws on the framework of 'possible selves' (Markus and Nurius, 1986), encouraging creative workers to discuss both positive and negative images of the self as they consider what they hoped to become, or feared becoming, in the past and into the future. For this study we adopted a commonly used definition of identity as a 'self-referential' description that provides contextually appropriate answers to the question 'Who am I?' (Ashforth et al., 2008). As Schnare et al (2011) point out, creative artists' 'possible selves' comprise a 'sense of self and vision of his or her future' (p. 94). The framework acknowledges the manner in which artist identity is fluid, generated through a lifetime of experience, socially motivated, and intrinsically refined. The range of questions then asked by the research team enables participants to explore and explain how they construct their identity.

The survey on which our investigation is based was administered in Perth, Australia, from 2010-2012. Participants were recruited through creative industries networks using respondent-driven sampling with multiple initial sources selected to represent Perth's creative industry sectors. Calls for participation were made through local media and industry press and associations; the survey was distributed in hard copy and by email. The 182 respondents represented a broad spectrum of creative occupations and employment types. They were aged from $18-80$, with $60 \%$ of them female.

Respondents were asked about the characteristics of their work, including main and secondary occupations, income and time allocations. They described the location of their creative work, their motivation and identity, their formal and informal learning, and gave basic demographic information including cultural background and patterns of relocation. Finally, they were invited to write freely about their creative work.

In all, participants responded to 48 questions, some of which were quantitative (for instance, age or average income from creative works) and others qualitative. The qualitative questions were integrated with the total survey.

8.1 In terms of professional identity, how do you answer if someone asks 'what do you do?'

8.3 If yes, (answer re identity changing) how does your answer change and how do you make that decision?

Reid, A., Bennett, D., \& Petocz, P. (In press). Creative workers' perceptions of worth: Understanding identity and motivation in a complex workforce. Australian Journal of Career Development. Accepted December 2015. 
9. What was your main activity on the last day of last month?

16. What were your unpaid time commitments?

19.3 If the amount of income derived from arts work has changed, what are the reasons?

25. What is the relationship between your non-arts roles and your arts practice?

27.5 Why would you allocate your time in this way?

31. Thinking back in time, what are the three most formative events in your career? (Event 1), (Event 2), (Event 3)

32.1 Can you identify an age, 'moment' or period of time when your career aspirations shifted?

48. Stories to tell

The survey was fairly lengthy and simply acquiring 182 responses to it suggests that creative workers were keen to tell their stories. For instance, the very last question asked participants to tell a story about their life. This story was expressed in between two or three paragraphs (the usual) to seven pages (the extreme).

\section{How Creative Workers Think about Themselves and their Work}

The survey included a number of free-response questions, and the findings that follow have been derived from the sum of these responses. A questionnaire normally demands a quantitative analysis (which we have carried out previously, see Bennett at al., 2014), but the written responses provide material that extends the analysis to favour the overall meaning contained in the responses. The extent of the written responses allowed us to adopt a phenomenological perspective, in which we looked for a rich description of an individual's creative working life, and also pooled the meanings from the 182 responses to develop an overall framework that enables explorations of workers' perceptions of worth. The final question, which focused on a personal story, provided detailed insight into the life world of each respondent, and also a means of investigating the context of their prior responses.

Each questionnaire was considered within a narrative framework (Connelly and Clandinin, 1990). This framework is based on the premise that people tell stories that are embedded within their personal social spheres. Our participants' narratives demonstrate the characteristics of their lives using words, phrases and images that illuminate the meaning they ascribe to certain situations. Our analysis focused on establishing the personal meanings found within each questionnaire, and then exploring the commonalities and differences between experiences. As Dillon (2011) suggests, Reid, A., Bennett, D., \& Petocz, P. (In press). Creative workers' perceptions of worth: Understanding identity and motivation in a complex workforce. Australian Journal of Career Development. Accepted December 2015. 
narrative inquiry can focus on the words that are provided, or it can expand through looking at the "processes of self-making" (p. 213).

The analysis was initiated using a 'naturalistic' coding process followed by a thematic reduction. The qualitative responses were firstly read from hard copy text in their entirety without pre-determined codes being applied. Firstly, the group read the texts from each individual participant. Then, we re-read the material looking at the collection of material for each question. Next, the research team discussed ideas that seemed apparent in the data. This process led to the production of some thirty keywords representing the ideas. The texts were then imported into analytic software and were coded using NVivo10 including paragraphs surrounding the key words. In this way the key ideas were kept with the participants' contexts. Other prominent ideas were also coded through this process using newly identified key words. Next, the coding was reviewed, with the data providing meaning and context to the key words.

NVivo10 software enables the analyst group to explore relationships between individual key words, whole paragraphs and ideas, the frequency of ideas within any text, the range of ideas that crop up in individual transcripts or across the whole. These key words were then truncated into themes and the process of re-coding commenced. In this way, several sweeps through the data enabled the final 'elements' to emerge (see Table 1). Each of the five elements (and their themes) is described in the following text using data - actual quotes - from respondents as evidence. We have used the idea of 'elements' to describe different key ideas that summarise the embedded themes. This word is deliberate as the participants in the student identify with ALL the elements when constructing their own stories throughout the entire survey material. Using the word 'elements', rather than 'categories', we are alerting readers to the importance of seeing the participants' experience as the 'process of self-making'.

Table 1: Elements of worth and key themes, as defined by creative workers

\begin{tabular}{ll}
\hline Elements of worth & themes \\
\hline Identity Representation & length, tone, social \\
\hline Motivation & calling, passion, resilience \\
\hline Catalysts of Creativity & life stage, life change, education \\
\hline Interaction with Society & impact, connection \\
\hline Recognition & funding, prizes, value
\end{tabular}

Reid, A., Bennett, D., \& Petocz, P. (In press). Creative workers' perceptions of worth: Understanding identity and motivation in a complex workforce. Australian Journal of Career Development. Accepted December 2015. 
The work and life situations of our participants are hugely varied. Many report participating in functional work as well as creative work and they are motivated by those situations in different ways. Pintrich and Schunk (1996) observed this in a study of students' expectations of value in an activity, finding a relation between a person's individual expectation of a situation and the importance they attributed to it. The authors noted that when students felt they had done well in some situation, it provided a loop of enjoyment and expectation that went alongside the activity. The situation became more important for the individual if a value was ascribed to it. O'Neill and MacPherson (2002, p. 32) described it this way: "a student who plays an instrument exclusively for the pleasure of performing with an ensemble will value music performance differently from a student whose intention is to become a professional musician." Our participants also describe this phenomenon, but for them there is an uneasy relationship between individual identity as creative workers, the exigencies of the work environment (which may or may not be in a creative field, or may be in both) and the activities that are intrinsically satisfying as a creative worker.

In the material presented below, direct quotes from our participants help us understand the complexities of motivation and the worth that their work has for them. Respondents are able to present their creative work through the specific lens of their life experience. Although their experiences are represented as elements and themes, there is considerable overlap between them. The participant narratives demonstrate this juxtaposition, and our identification of elements and themes should be used only as a means of understanding the complexity of their lives. Quotes selected to illustrate elements and themes were those that were the most succinct and provided the greatest variety. Meaning is derived from the whole pool of responses, but the small extracts provided illustrate the elements and themes rather than being indicative of a single person's experience.

\section{Element 1: Identity Representation}

Identity representation concerns the way in which creative workers present their identities to others. The first theme of this element concerns 'length'. Those who provide brief responses usually have a positive view of their work, and tend to provide short and confident responses elsewhere in the survey. Hence, the brief responses also seem to represent a confidence in relation to creative work and identity. By contrast, Reid, A., Bennett, D., \& Petocz, P. (In press). Creative workers' perceptions of worth: Understanding identity and motivation in a complex workforce. Australian Journal of Career Development. Accepted December 2015. 
other respondents provide a far longer response. For some, such a response clarifies the style and mix of the work they did. For others, the longer response also shows how their creative identity shifts depending on their perception of the audience. The second theme is the 'tone' of each response. Here the respondent supplies a qualitative judgment of their work, articulated positively, negatively or conditionally. The third 'social' theme shows how respondents identify who they are in specific social situations. It also reveals how the situation provides an opportunity for the person to disclose to people what they think about their work. In some cases, the lack of disclosure shows an intrinsic discomfort with their work. Responses within each theme are illustrated in the following text.

\section{Length - brief}

Art lecturer and artist

I am a painter

Novelist

Musician

I am an Artist

\section{... or more extended}

I have a portfolio career - 1/3 business, 1/3 mentoring CEOs, 1/3 as an opera singer

In a conservative setting I say I 'run a sustainability consultancy and work as a creative environmentalist' but if I'm feeling more playful I say 'I'm a trans disciplinary maestro'

I am a glassmaker (for the uneducated I am a glass blower - no not like the guy at the supermarket - I work with a furnace with blowing irons)

\section{Tone}

I hesitate, sometimes mumble, or sometimes proudly state (depending on the company) that I'm a choreographer and dance artist. Or often start with 'artist', then elaborate if they ask

I tell them what my day job is

I draw people at posh parties

I say I am an unemployed actor

Reid, A., Bennett, D., \& Petocz, P. (In press). Creative workers' perceptions of worth: Understanding identity and motivation in a complex workforce. Australian Journal of Career Development. Accepted December 2015. 
Creative people are simply creative and totally mis-understood by corporate, retail or any other profession

\section{Social}

Answer is determined by the knowledge of art making of the person to whom I am speaking. If their paradigm is narrow, I say I teach art. It's easier for me as I am primarily into non-objective painting. Too hard to explain let alone defend.

I really do not want to talk about my practice to most people that I meet, it is all too difficult to readily explain my chosen field of activity.

In certain social situations it is not good to say you are an artist as people assume you're on the dole, a bludger, or they want to know the specifics of how you earn your income and how much you earn. Generally the majority of people are fine, but there is quite a vociferous minority who do not see being an artist as being a responsible member of society.

\section{Element 2: Motivation}

This element has three themes. The quotations in the 'calling' theme show that for some creative workers there has been no choice in vocation; they have always known that they would be a creative worker, and the tone of these quotations is usually positive. The 'passion' theme illustrates how respondents maintain their positive stance towards creative work, given that, intrinsically, there is no other suitable choice for them. The final theme is 'resilience'. Here, participants may have a calling or passion for their chosen field of work, but they acknowledge that finding and executing work can be problematic. Quotations in this theme demonstrate how dedicated the creative workers are to their field.

\section{Calling}

Deciding at 20 years of age, after three years full time work in a medical laboratory, that I did not value money, but creativity. That I could not live my life 'earning a living', but had to live my life creatively above all other considerations. And quitting my full time job, getting a part time one, and beginning to design and make clothes, write songs... cute really, looking back, but a very real and crucial moment.

Reid, A., Bennett, D., \& Petocz, P. (In press). Creative workers' perceptions of worth: Understanding identity and motivation in a complex workforce. Australian Journal of Career Development. Accepted December 2015. 
I do Art because it is ALL I am good at, without it, I'm nothing.

When I was 8 I wanted to be a photographer. When I was 16 I wanted to be a photographer. When I was 21 I wanted to be a photographer. When I was 25 I finally listened to myself and became a photographer.

I have always wanted to become an artist ever since from the age of 3.

\section{Passion}

Everyone in the arts always goes through the 'should I really be doing this? Am I in the right career? I'm always broke, should I give up?' But you should never give up, yes it is difficult but it is our passion and you can't turn your back on that burning desire to want to do what you really love with your life. The ultimate goal doesn't shift of wanting to be an actor, you just have to juggle other things around it to still be able to support yourself.

I would like to work as a full time professional artist, though it seems an impossible dream. Nevertheless I will not give up.

\section{Resilience}

Much harder to sustain full-time practice. Less money than I had imagined. We are at the bottom of the economic pile! I was never aware of this as a student. The need for freelance artists to multi-task and juggle their numerous jobs in order to make decent money is a very exhausting act and in my case, led to a 'burn out' after 6 years of practice.

I'm way less 'successful' than what I dreamed of at 22. I wanted the glamour, the going from one interesting fun role to another, and the public recognition. Instead I'm making a semi-decent-to-poor living from corporate theatre and the odd TV commercial, doing very little paid 'real' theatre which was my passion. But that's the reality of the industry I guess.

\section{Element 3: Catalysts of Creativity}

In this element respondents recognize that different life events influence their ability and opportunity to be a part of the creative workforce. Three themes are distinctly recognizable in this element. Firstly, the 'life stage' of the respondent emerges as crucial in making the decision to work as a creative worker. Second, some respondents

Reid, A., Bennett, D., \& Petocz, P. (In press). Creative workers' perceptions of worth: Understanding identity and motivation in a complex workforce. Australian Journal of Career Development. Accepted December 2015. 
experienced a 'life-change' event such as death, marriage, birth, or retirement, and these events served as a catalyst for their creative works. Finally, 'education' (or the lack of it) seems to be a specific important catalyst.

\section{Life Stage}

I am not a parent yet, I only really have myself and home to look after. Dedicating all of my time to my art practice is perhaps a bit of a luxury that I might not always be able to continue.

There are various key moments: choosing art ahead of money at 20 (as explained above); choosing music over other options at around 21, shifting to visual arts at 28, and to writing at around 34. Aspiring to publish books during my first ten years of writing; and then in the past five years having to aspire instead to keep a roof over my head and pay the rent as it became less feasible to live on low income.

\section{Life Change}

When I was widowed at the age of 47 I knew that I would redeem this turn of fate through devotion to my arts practice. I thought it would happen 'overnight', because I had been writing for publication - though not 'creative writing' AND at a much less intense level - since my twenties. It has taken 13 years so far and I do not think I am 'there yet'!!! And I have learnt that (for me), unlike commercial employment, an arts career is not something I can achieve 'on my own'; all my shifts have been due to collective support.

\section{Education}

I quit my job and enrolled to study a diploma of music business at TAFE and never looked back.

Beginning my Masters in Curatorial \& Exhibition Management - I looked around and realised the majority of my fellow students were more interested in the business of hanging paintings than planting seeds for revolution, I dropped out and quit the arts industry.

I'm mostly a self taught artist.

\section{Element 4: Interaction with Society}

The previous elements were bound up with respondents' self-identity. This element Reid, A., Bennett, D., \& Petocz, P. (In press). Creative workers' perceptions of worth: Understanding identity and motivation in a complex workforce. Australian Journal of Career Development. Accepted December 2015. 
is somewhat different as it expresses the extrinsic worth of the creative workers work. There are two themes in this element: 'impact' and 'connection'. The 'impact' theme describes the social outcomes of the respondents' work, and focuses on the effect that creative work has on the recipients. The work can be community based or commercial, and the work outcomes are invariably well received by both these groups. The 'connection' theme entwines the extrinsic and the intrinsic, the effect on the audience and the resulting affect on the creative artist herself or himself. In a sense, the creative work is seen as a collaborative expression between audience and artist.

\section{Impact}

I would want it [my practice] to be spread fairly evenly because you want to reach all types of audiences, your commercial audience will take care of the money in the future, the not for profit is pretty much what we all do anyway because it is our passion, our lives our drive and it is not about the money for most of us so we would love to keep in touch with the community and get more people involved in the arts.

I also think the unmediated community sector allows arts to flourish in new and exciting ways. The commercial sector doesn't interest me on the whole because I think anything that is driven by a bottom line is too narrow and limiting to really engage with art in a truthful way.

\section{Connection}

I travelled up the Kimberley with the WASO's [West Australian Symphony Orchestra] "ECHO” ensemble - an educational mini-orchestra. We performed to kids in remote towns and communities, and often this was the first time that these kids had ever experienced classical music in any form. To see the joy and wonder on their faces was a great privilege.

Because the need, and therefore the appreciation, of 'pure art' is greater in the not for profit and community sectors. In this sense, as an artist I can better express my arts in those sectors and feel a deeper interaction with the audience.

\section{Element 5: Recognition}

This is maybe the most important element in understanding creative workers' perception of worth. Although we have not presented our findings in terms of

Reid, A., Bennett, D., \& Petocz, P. (In press). Creative workers' perceptions of worth: Understanding identity and motivation in a complex workforce. Australian Journal of Career Development. Accepted December 2015. 
frequencies, focusing rather on the overall meaning of the quotes, we can report that recognition of creative work was an idea that permeated nearly all responses. Three themes were discerned in this element. The first, 'funding', describes situations where respondents spoke about the way their work is supported financially. It seems that most creative workers, across most art forms, find that their work is very poorly remunerated. A few respondents recognize that 'prizes' are a part of the creative worker funding models. Prize winning has a motivating effect (to continue) and a legitimizing effect (I've made it!). Finally, 'value' demonstrates how respondents appreciate the social and financial rewards derived from their work. As with 'prizes', value recognition provides respondents with the impetus to continue their creative work.

\section{Funding}

I am not interested personally in community projects and I think people should be rewarded for the work they do.

I haven't been successful (so far) with any of my funding and performance applications this year.

I can't afford to be an artist. I am not established, to get grants you need to have work out there as a writer or artist. There needs to be starter grants for older artists, who did not get any of the youth grants due to of career/ parenting commitments.

I've managed to 'mash-up' both [creative and other careers] rather than exist doing 'one thing'. An arts career was too financially unviable for me to pursue so I undertook psychology and now that I can earn a living from that, have turned back to the arts. The two now exist side by side. Quite wonderful really!

\section{Prizes}

Winning a song competition at the age of 16 , which led on directly to working with a touring band and have never stop working in that field since. Prior to that, at the age of 15, I ran away as joined a circus on the east coast of Australia.

To be invited as an emerging artist at the PC art awards. Then have my works sold out on the same night and have interest from a gallery which I am now with.

\section{Value}

It represents, for me, a full year and a half of hard slog, getting up ridiculously

Reid, A., Bennett, D., \& Petocz, P. (In press). Creative workers' perceptions of worth: Understanding identity and motivation in a complex workforce. Australian Journal of Career Development. Accepted December 2015. 
early every morning to write a few thousand words, juggling childcare and parttime work in order to complete something that has earned me approximately $\$ 500.00$ (for one Chapter publication as a short story and a Radio National adaptation \& broadcast). I calculated once that this represented the following: Approx 547 days $x 2$ hours work $(5 \mathrm{am}$-7am) $=1095$ hours $=$ approx $\$ 0.50$ cents per hour - or $-\$ 500.00$ for 90,000 words $=$ approx $\$ 0.005$ cents per word. 'Nuff said!

Putting our minimum rate up to $\$ 100 / \mathrm{hr}$ and getting more work than ever. People value your work more when they pay you more.

\section{Discussion and Conclusions}

The five elements that we have identified - identity representation, motivation, catalysts of creativity, interaction with society, and recognition - combine to provide a picture of creative workers' lived experience of their unusual work life. It seems that the continuation of important cultural work is dependent on the will and passion of this complex workforce. Our data show that creative workers' identity as creative artists underpins their motivations to work, sustains their creative interest when not in creative work, and impacts on the manner in which they relate to the world at large. Sometimes, creative workers integrate their personal creative skills and approaches into different workplaces; in economic terms, creative work undertaken in another economic sector is referred to as 'embedded' work and may be the major, or even the only, site of that creative practice.

The responses quoted earlier show how creative workers commonly adapt their role identities to better fit their personal identity or sense of self (Kreiner et al., 2006; Pratt, Rockmann and Kaufmann, 2006). They also illustrate several different strategies for coping with multiple and/or conflicted identities including compartmentalizing competing identities to avoid direct contact and comparison, and creating boundaries between potentially conflicting selves to ensure the time and focus required for creative work (Ashforth, 2001; Shepherd, 2003). There were indications of coping mechanisms including ambiguity (Corley and Gioia, 2004), threat (Elsbach and Kramer, 1996) disidentification (Elsbach and Bhattacharya, 2001), and aspirational statements comparing current and desired work.

The differentiation between a job, a career, and a calling is articulated by Reid, A., Bennett, D., \& Petocz, P. (In press). Creative workers' perceptions of worth: Understanding identity and motivation in a complex workforce. Australian Journal of Career Development. Accepted December 2015. 
Wrzesniewski et al. (1997, p. 25): "People with callings find that their work is inseparable from their life. A person with a calling works not for financial gain or career advancement, but instead for the fulfilment that doing the work brings to the individual." This points to the deeper, psychological meaning associated with 'calling' and the strong emotional attachment to the choice. Other research suggests that individuals who view their career as a calling are more likely to be satisfied with and committed to their work, and less likely to withdraw. However, high expectations of such a career may leave employees vulnerable to disillusionment (Duffy et al., 2011), with implications for the psychological contract that underpins expectations, commitment and satisfaction.

Recognition is an important aspect of working life in general, not only in the creative industries, and previous research has stressed the importance of intrinsic rewards of work. Hertzberg (1987) identified links between intrinsic rewards and intrinsic motivation, and pointed out that intrinsic factors are a stronger predictor than extrinsic factors of behavioural intentions. If a job is to be intrinsically motivating, it needs to provide opportunities for feedback, allow the job holder to use his or her abilities, and allow for a high degree of autonomy (Armstrong and Brown, 2006). Frey (1975) points out that the neoclassical paradigm for economic motivation is to combine incentives and rewards. Extrinsic rewards and incentives often form a significant component of the positive relationship to motivation, but monetary payments may displace intrinsic motivation, and so act as a disincentive (Deci, 1975). Maybe a key point here is that many other workers receive a level of recognition in the form of salary, but this is often not easily accessible for creative workers.

In general, intrinsic success in terms of self-identity and meeting personal and professional goals is a growing concern across the labour market. In order to achieve intrinsic success, workers expand their behaviours, skills and competencies, and networks. However, success and esteem are also determined by extrinsic drivers such as the acceptance of, and demand for, an individual's work by significant others, social groups and the community. What has emerged from existing research on the motivating potential of extrinsic rewards, particularly money, is that it is complex - and money alone is not enough. Workers judge the quality of their work by the intrinsic satisfaction gained and whether they feel their work environment is supportive (Thompson, 2003), and many studies have demonstrated the positive organizational outcomes of having an Reid, A., Bennett, D., \& Petocz, P. (In press). Creative workers' perceptions of worth: Understanding identity and motivation in a complex workforce. Australian Journal of Career Development. Accepted December 2015. 
affectively committed workforce (Mathieu and Zajac, 1990). This has led to increased awareness that intrinsic rewards are central to employee attraction and retention, even for workers who are largely or wholly self-employed.

Identity, motivation, interaction with society and recognition appear to be central to creative workers' narratives of work and living, and this has implications for their employers. As Kristof-Brown and colleagues point out (2005), dealing with (workrelated) identities is important. In line with Pintrich and Schunk's (1996) observation that work situations attract increased individual meaning if value is ascribed to them, workers who feel that their ideas and values match those of their organization are more likely to make a commitment to that organization. However, for creative workers there is another dimension: recognition of individual goal structures within those situations (as described by Mehr, 1996) is likely to generate high-creative individuals motivated to do well, particularly in situations that explicitly allow for creative action.

Research indicates that intrinsic factors such as learning opportunities and career development instead of, or alongside, financial rewards appear to be a critical determinant in motivation and retention (Armstrong and Brown, 2006). There is evidence that younger workers are also intrinsically motivated, even early in their career, and that job characteristics that are specifically intrinsic in nature are directly correlated to job satisfaction and commitment (Lubbers et al., 2005). These intrinsic factors contribute to creative workers' views of their work and careers.

The narratives constructed by our participants throughout the questionnaire demonstrate the importance of the interplay between self, situation and feelings of worth. There exists a tension between creative purpose and economic purpose, which in the creative industries can take a complex form. The point at which creative purpose meets economic purpose helps to shape individual preferences and motivations, and this point is likely to change according to personal, social and economic circumstances. In terms of management, the autonomy and creative space needed for creative labour to be intrinsically satisfying make it difficult to monitor, codify or control. Banks (2010) noted the tension between the need for creative workers to create an independent nexus of creativity, labour freedoms and skilled artisanal production, while at the same time meeting commercial imperatives, and, in the opposite direction, the necessity for managers to ensure that those artistic freedoms are not destroyed. The quotations from our respondents show that creative workers would agree with Banks as they strive for Reid, A., Bennett, D., \& Petocz, P. (In press). Creative workers' perceptions of worth: Understanding identity and motivation in a complex workforce. Australian Journal of Career Development. Accepted December 2015. 
artistic autonomy but are equally reliant on possible work opportunities that use their specific creative or generic creative skills and knowhow.

The research discussed in this paper focuses on the experience of creative workers in Western Australia. We have replicated this study in Europe and Canada and are currently undertaking the analysis of the data. Studies like this are highly contextual and the political, cultural, and work environments of different countries, and regions of countries, could make differences for creative workers' view of the value of their work.

\section{References}

Armstrong, M. and Brown, D. (2006), Strategic Reward: Making it Happen, Kogan Page, United Kingdom.

Ashforth, B. (2001), Role Transitions in Organizational Life: An Identity-based Perspective, Lawrence Erlbaum, Mahwah NJ.

Ashforth, B., Harrison, S. and Corley, K. (2008), "Identification in organizations: an examination of four fundamental questions", Journal of Management: Vol. 34 No. 3, pp. 325-374.

Australia Council (2014), Arts in Daily Life: Australian Participation in the Arts, Sydney.

Australian Bureau of Statistics (2014), Australian National Accounts: Cultural and creative activity satellite accounts, experimental, 2008-09 [5271.0], Commonwealth of Australia, Canberra.

Banks, M. (2010), “Autonomy guaranteed? Cultural work and the 'art-commerce relation", Journal for Cultural Research, Vol. 14 No. 3, pp. 251-269.

Bennett, D. and Bridgstock, R. (2015), “The urgent need for career preview: Student expectations and graduate realities in music and dance", International Journal of Music Education, Vol. 33 No. 3, pp. 263-277.

Bennett, D., Coffey, J., Fitzgerald, S., Petocz, P. \& Rainnie, A. (2014), "Beyond the creative: Understanding the intersection of specialist and embedded work for creatives in metropolitan Perth", in Hearn, G., Bridgstock, R., Goldsmith, B. and Rodgers, J. (eds), Creative Work Beyond the Creative Industries: Innovation, Employment, and Education, Edward Elgar Publishing, Cheltenham, pp. 158-174.

Bennett, D., Reid, A. and Petocz, P. (2015), "Student stories of creativity in music Reid, A., Bennett, D., \& Petocz, P. (In press). Creative workers' perceptions of worth: Understanding identity and motivation in a complex workforce. Australian Journal of Career Development. Accepted December 2015. 
higher education: Creativity 'on the other side of the divide"', in Burnard, P. and Haddon, L. (eds), Activating Diverse Musical Creativities: Teaching and Learning in Higher Music Education, Bloomsbury, London, pp. 21-35.

Frey, B. (1975), Not Just for The Money. An economic theory of personal motivation, Edward Elgar Publishing, Cheltenham.

Connelly, F.M. and Clandinin, D.J. (1990), "Stories of experience and narrative inquiry”, Educational Researcher, Vol. 19 No. 5, pp. 2-14.

Corley,K. and Gioia, D. (2004), "Identity ambiguity and change in the wake of a corporate spin-off”, Administrative Science Quarterly, Vol. 49 No. 2, pp. 173-208.

Cunningham, S. (2011), "Developments in measuring the 'creative' workforce", Cultural Trends, Vol. 20 No. 1, pp. 25-29.

Deci, E. (1975), Intrinsic motivation, Plenum Publishing Company, New York.

Dillon, L. (2011). Writing the self: the emergence of a dialogic space. Narrative Inquiry. Vol 21, No.2 pp 213-237.

Duffy, R., Dik, B. and Steger, M. (2011), "Calling and work-related commitment as a mediator", Journal of Vocational Behavior, Vol. 78 No. 2, pp. 210-218.

Duxbury, N., Jeannotte, M.S., Andrew, C., and Mateus, M.J. (2012). "Culture in sustainable communities: improving the integration of culture in community sustainability policy and planning in Canada and Europe”, presented at International Conference on Cultural Policy Research (ICCPR) 2012: 'Culture, politics and cultural policies', Barcelona, Spain, July.

Eikhof, D. and Haunschild, A. (2006), "Lifestyle meets market: bohemian entrepreneurs in creative industries", Creativity and Innovation Management, Vol. 15 No 3, pp. 234-241.

Elsbach, K. and Bhattacharya, C.B. (2001), "Defining who you are by what you're not: organizational disidentification and the national rifle association", Organization Science, Vol. 12 No. 4 pp. 393-413.

Elsbach, K. and Kramer, R. (1996), “Members' responses to organizational identity threats: encountering and countering the Business Week rankings", Administrative Science Quarterly, Vol. 41 No. 3, pp. 442-477.

Hall, D.T. (1976), Careers in Organizations, Goodyear Publishing Company, Glenview, Illanois.

Handy, C. (1989), The age of unreason, Harvard Business School Press, Harvard.

Reid, A., Bennett, D., \& Petocz, P. (In press). Creative workers' perceptions of worth: Understanding identity and motivation in a complex workforce. Australian Journal of Career Development. Accepted December 2015. 
Herzberg, F. (1987), “One more time: how do you motivate employees?" Harvard Business Review, Vol. 65 No. 5 pp. 109-120.

Kreiner, G., Hollensbe, E. and Sheep, M. (2006), "Where is the 'me' among the 'we'? Identity work and the search for optimal balance", The Academy of Management Journal, Vol. 59 No. 5 pp. 1031-1057.

Kristof-Brown, A., Zimmerman, R. and Johnson, E. (2005), "Consequences of individuals' fit at work: a meta-analysis of person-job, person-organization, persongroup and person-supervisor fit”, Personnel Psychology, Vol. 58 No. 2, pp. 281-342.

Lubbers, R., Loughlin, C. and Zweig, D. (2005), "Common pathways to health and performance: Young workers' job Self-Efficacy and Affect”, Journal of Vocational Behaviour, Vol.67 No. 2 pp.199-214.

Markus, H.R and Nurius, P. (1986), American Psychologist, Vol. 41 No. 9 pp. 954-969.

Maslow, A. (1943), “A theory of human motivation”, Psychological Review, Vol. 50 No. 4 pp. 370-396.

Maslow A (1970). Religions, values, and peak experiences, Kappa Delta Pi, New York.

Mathieu, J. and Zajac, D. (1990), “A Review and Meta-Analysis of the Antecedents, Correlates, and Consequences of Organizational Commitment", Psychological Bulletin, Vol. 108 No. 2 pp. 171-194.

Mehr, D. G. (1996), Goal Structure in Creative Motivation, $\mathrm{PhD}$ diss. State University of New York at Buffalo.

O’Neill, S. and McPherson, G. (2002), “Motivation”, in The Science and Psychology of Music Performance: Creative Strategies for Teaching and Learning, in Parncutt, R. and McPherson, G. (eds), Oxford Scholarship Online, 31-46.

Nicholson, V. (2003), Among the Bohemians: Experiments in Living 1900-1939, Penguin, London.

Parry, A. (1933), Garrets and Pretenders: A history of Bohemianism in America Covici-Friede, USA.

Pintrich, P. and Schunk, D. (1996), The Role of Expectancy and Self-Efficacy Beliefs Motivation in Education: Theory, Research \& Applications, Englewood Cliffs, USA.

Pratt, M.G and Foreman, P.O. (2000), "Classifying managerial responses to multiple organizational identities", Academy of Management Review Vol. 25 No. 1 pp. 18-42.

Pratt, M.G., Rockmann, K. and Kaufmann, J.B (2006), "Constructing professional identity: The role of work and identity learning cycles in the customization of

Reid, A., Bennett, D., \& Petocz, P. (In press). Creative workers' perceptions of worth: Understanding identity and motivation in a complex workforce. Australian Journal of Career Development. Accepted December 2015. 
identity among medical residents", Academy of Management Journal, Vol. 49 No. 2 pp. 235-262.

Reid, A., Abrandt Dahlgren, M., Dahlgren, L.O. and Petocz, P. (2011). From Expert Student to Novice Professional. Springer, Science+Business Media, London.

Schnare, B., MacIntyre, P. and Doucette, J. (2011). Possible selves as a source of motivation for musicians. Psychology of Music. Vol 40, No.1 pp.1-18.

Shepherd, D.A., (2003), "Learning from business failure: Propositions of grief recovery for the self-employed", Academy of Management Review, Vol. 28 No. 2 pp. 318-328.

Taylor, S., \& Littleton, K. (2012). Contemporary Identities of Creativity and Creative Work. Aldershot: Ashgate.

Thompson, R.S. (2003), The perception of servant leadership characteristics and job satisfaction in a church-related college, Unpublished dissertation, Indiana State University.

Throsby, D. (2008). "Creative Australia: The arts and culture in Australian work and Leisure," Occasional Paper 3/2008. Canberra: Academy of the Social Sciences in Australia.

Wrzesniewski, A., McCauley, C., Rozin, P. and Schwartz, B. (1997), “Jobs, careers, and callings: People's relations to their work", Journal of Research in Personality Vol. 31 pp. 21-33.

Reid, A., Bennett, D., \& Petocz, P. (In press). Creative workers' perceptions of worth: Understanding identity and motivation in a complex workforce. Australian Journal of Career Development. Accepted December 2015. 